\title{
Knowledge of the physiology of spore-forming bacteria can explain the origin of spores in the food environment
}

\author{
Emilie Gauvry ${ }^{\mathrm{a}, *}$, Anne-Gabrielle Mathot ${ }^{\mathrm{a}}$, Ivan Leguérinel ${ }^{\mathrm{a}}$, Olivier Couvert ${ }^{\mathrm{a}}$, \\ Florence Postollec ${ }^{\mathrm{b}}$, Véronique Broussolle ${ }^{\mathrm{c}, \mathrm{d}}$, Louis Coroller ${ }^{\mathrm{a}}$ \\ ${ }^{\text {a } U n i v e r s i t e ́ ~ d e ~ B r e s t, ~ E A 3882, ~ L a b o r a t o i r e ~ U n i v e r s i t a i r e ~ d e ~ B i o d i v e r s i t e ́ ~ e t ~ E c o l o g i e ~ M i c r o b i e n n e, ~ U M T ~ S p o r e-R i s k, ~} 6$ rue de l'Université, Quimper, France \\ ${ }^{\mathrm{b}}$ ADRIA Développement, UMT14.01 Spore-Risk, Z.A. de Creac'h Gwen, Quimper, France \\ ' INRA, UMR408 Sécurité et Qualité des Produits d'Origine Végétale, F-84000 Avignon, France \\ ${ }^{\mathrm{d}}$ Avignon Université, UMR408 Sécurité et Qualité des Produits d'Origine Végétale, F-84000 Avignon, France
}

\begin{abstract}
Spore-forming bacteria are able to grow under a wide range of environmental conditions, to form biofilms and to differentiate into resistant forms: spores. This resistant form allows their dissemination in the environment; consequently, they may contaminate raw materials. Sporulation can occur all along the food chain, in raw materials, but also in food processes, leading to an increase in food contamination. However, the problem of sporulation during food processing is poorly addressed and sporulation niches are difficult to identify from the farm to the fork. Sporulation is a survival strategy. Some environmental factors are required to trigger this differentiation process and others act by modulating it. The efficiency of sporulation is the result of the combined effects of these two types of factors on vegetative cell metabolism. This paper aims to explain and help identify sporulation niches in the food chain, based on features of spore-former physiology.
\end{abstract}

Keywords: Sporulation initiation; Environmental factors; Food process; Spore-former

\section{Introduction}

Bacterial spores are resistant to physical and chemical treatments; they are able to survive food processes, to persist in the food industry environment and to be disseminated in the food chain [1]. When a spore encounters favorable conditions, it can germinate and the emerging vegetative cell can grow in foods until it reaches concentrations which make food unfit for human consumption by altering food safety or quality. For

* Corresponding author.

E-mail addresses: emilie.gauvry@univ-brest.fr (E. Gauvry), AnneGabrielle.Mathot@univ-brest.fr (A.-G. Mathot), ivan.leguerinel@univ-brest.fr (I. Leguérinel), Olivier.Couvert@univ-brest.fr (O. Couvert), florence. postollec@adria.tm.fr (F. Postollec), veronique.broussolle@avignon.inra.fr (V. Broussolle), louis.coroller@univ-brest.fr (L. Coroller). example, Bacillus cereus and Clostridium perfringens were responsible, respectively, for $23 \%$ and $11 \%$ of food-borne diseases in 2013 in France, while others, such as Bacillus licheniformis, have various enzymatic capacities, making them a major source of food spoilage [2,3]. Spore-forming bacteria are also able to persist in the food industry by forming biofilms that are resistant to cleaning processes [4-6]. These properties make spore-forming bacteria the major hazard in the thermal processing of foods $[7,8]$.

The presence of spores in end products can be explained by initial contamination of raw materials [6,9], crosscontamination in the food industry $[10,11]$ and production of spores during food processing [12]. Sporulation of Bacillus and some Clostridium species has been extensively studied and described at morphological, metabolic and physiological levels $[8,13-15]$. Knowledge of the physiology of spore- 
forming bacteria might help to predict sporulation environments in the food chain and consequently, to optimize food processes so as to limit the occurrence of spores.

In order to identify potential sporulation environments from the farm to the fork, it is necessary to know what initiates and modulates sporulation. Environmental factors can be classified into two types: triggers and modulating factors of sporulation that impact sporulation ability via metabolic pathways. In most cases, many factors are involved in modulating sporulation and their effects are interdependent. Identified sporulation niches in different food processes highlight the importance of considering the combined effects of environmental factors and their sequential role in triggering sporulation. Here, three cases in which sporulation has been reported are developed in order to illustrate this aspect.

\section{Sporulation triggers}

\subsection{Nutrient starvation}

Spore-formers initiate sporulation when environmental conditions become too adverse to allow them to survive as vegetative cells. Interestingly, there are only two determining factors that trigger sporulation: nutrient starvation and cell density. These two triggers lead to activation of the molecular master regulator of sporulation Spo0A by phosphorylation. The activated regulator $\mathrm{Spo} 0 \mathrm{~A} \sim \mathrm{P}$ then initiates the sporulation process.

Sporulation is mainly triggered by nutrient starvation; however, this process requires energy. Consequently, sporulation must be initiated while there are still enough nutrients to complete sporulation. Nutrient starvation concerns either amino acids or carbon sources and even minerals. In most cases, starvation is characterized by (i) a decrease in the internal concentration of branched chain amino acids (BCAAs), (ii) a decrease in the pool of guanosine triphosphate (GTP) which is the nutrient availability indicator and (iii) the conversion of GTP into an alarmone, guanosine pentaphosphate or tetaphosphate (p)ppGpp, involved in the stringent response (Fig. 1). CodY is a regulator that senses and binds BCAAs and GTP [16]. Binding forms of CodY repress early sporulation genes, including the master regulator of sporulation Spo0A. Consequently, a decrease in GTP levels allows transcription of the sporulation genes.

Triggering sporulation by nutrient starvation is dependent on the nature of the carbon source deprived. As an example, sporulation of $C$. perfringens is repressed by high concentrations $(>15 \mathrm{mM})$ of lactose, mannose and sucrose, but is not affected by the presence of galactose and fructose [18]. Conversely, glucose stimulates the sporulation of Clostridium acetobutylicum [19], while for Bacillus thuringiensis, sporulation is more efficient in the presence of glucose $(70 \%$ sporulation) than in the presence of lactose (30\% sporulation) [20].

Sporulation can be either triggered or inhibited by carbon metabolism pathways. As an example, the catabolite control protein $\mathrm{A}(\mathrm{CcpA})$ is a regulator that senses the availability of carbon sources and controls genes involved in sugar uptake, amino acid metabolism and fermentation. It can inhibit or activate sporulation depending on the Clostridium species [21]. This regulator is essential for efficient sporulation in $C$. perfringens [22], whereas it inhibits sporulation in Clostridium difficile by inhibiting expression of sensor histidine kinase CD1579 (Fig. 1) [21]. The ScoC protein is also a catabolitedependent actor of sporulation in Bacillus subtilis. In the presence of carbon sources, ScoC inhibits production of oligopeptide permease (Opp) [23] and, consequently, the entry of pheromones through Opp (see Section 2.2). ScoC also inhibits transcription of $\sin I$, an antagonist of $\sin R$ that negatively affects production of the master regulator of sporulation Spo0A [24] (Fig. 1).

The ability to sporulate in soil environments also depends on the presence of organic material. Starvation can occur in soils due to a leaching effect caused by rainfall or simply due to the nutrient poverty of soil (step A in Fig. 2). The ability to sporulate in food depends on its carbohydrate composition. For example, C. acetobutylicum P262 produces more spores in the presence of glucose than in the presence of starch or cellobiose [25]. Moreover, vegetative cells can develop as microcolonies in food according to food textures, like in fermented sausages or in cheese. Growth in a reduced space implies that nutrient starvation can occur more rapidly. In addition, starvation may be due to competition with other flora for nutrients. Starvation conditions can also occur in the food industry during water cleaning processes or in scalding tanks for vegetables and poultry (steps $\mathrm{K}$ and O, Fig. 2).

\subsection{Quorum sensing}

\subsubsection{Cell density}

Cell-to-cell communication via quorum-sensing signals allows detection of "sufficient nutrient per cell" information so as to retain enough energy for the entire sporulation process [26]. This explains why quorum-sensing and starvation pathways regulate each other (for more details, see [27]).

Unlike nutrient starvation, which stimulates production of Spo0A, sensing of cell density acts by promoting activation of Spo0A by its phosphorylation (Fig. 1). Briefly, the activation of Spo0A is the result of a phosphorylation cascade that is initiated by histidine kinases (HK) KinA, B, D and E in $B$. subtilis. These proteins allow environmental stimuli to be sensed. Once they have been stimulated, they autophosphorylate and end phosphorylating Spo0A via a phosphorylation cascade through $\mathrm{SpoOF}$ and $\mathrm{Spo0B}$ in B. subtilis (Fig. 1). Phosphorylation of Spo0A $\sim \mathrm{P}$ can be reversed by aspartate phosphatases such as SpoOE [28] and by the Rap phosphatases (RapA to RapK), which act by dephosphorylating the intermediary Spo0F $\sim \mathrm{P}$ [29].

Bacterial cells produce peptide pheromones such as $\mathrm{Phr}$ peptides and extracellular differentiation factor A (EDF-A) which are secreted in the extracellular medium. As vegetative cells grow, the concentration of external pheromones increases until it reaches a concentration at which pheromones are reimported inside other cells through Opp (Fig. 1) [30,31]. 
Version définitive du manuscrit publiée dans / Final version of the manuscript published in :

Research in Microbiology (2016), 10 p., DOI: 10.1016/j.resmic.2016.10.006

Journal homepage : http://www.elsevier.com/locate/resmic

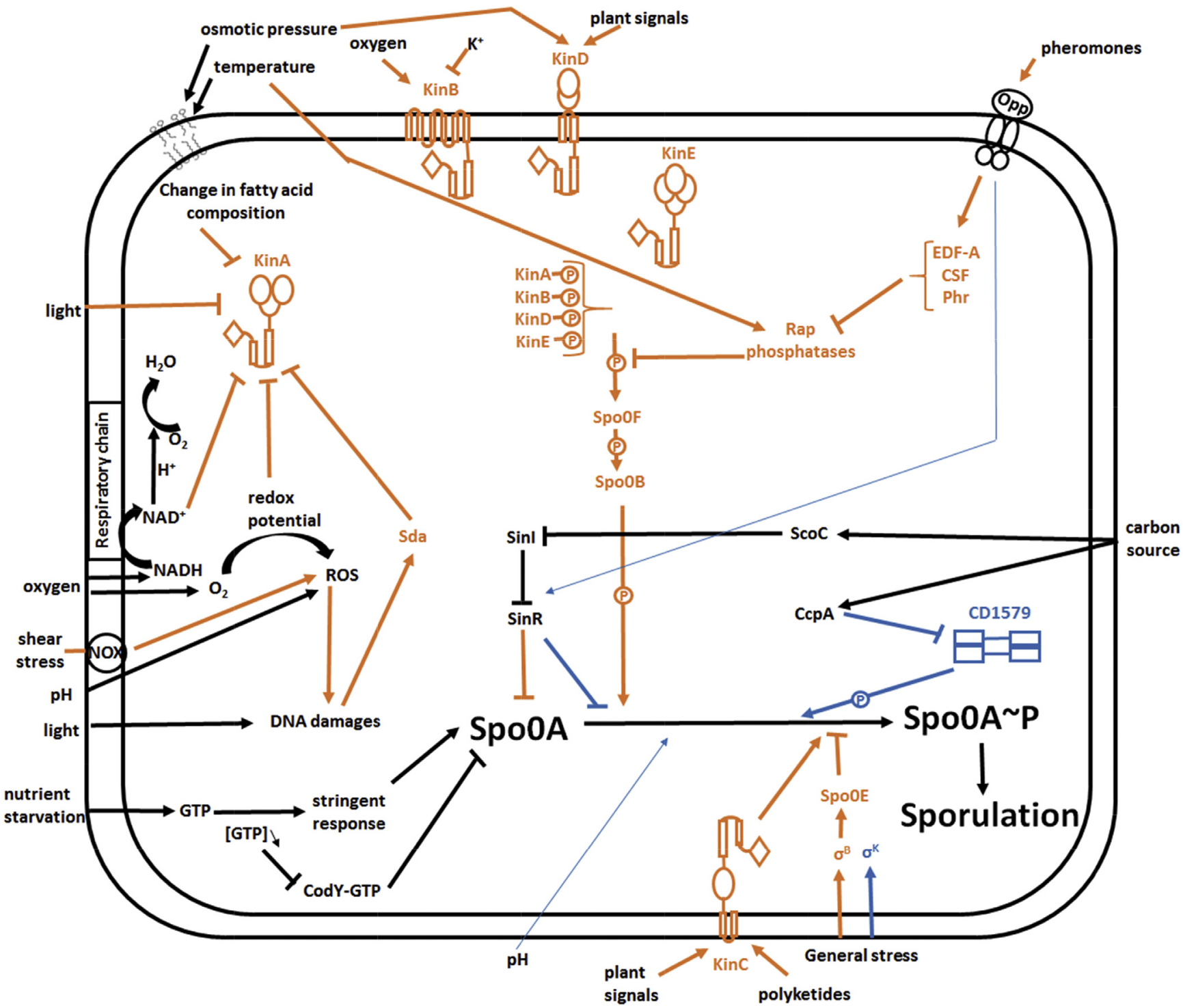

Fig. 1. Effects of environmental factors on the initiation sporulation pathways of Bacillus and Clostridium. Some sporulation pathways are specific to Clostridium (in blue) and Bacillus (in orange) and some elements are common to both, or found in both (in black). Activation pathways $(\rightarrow$ ) and inhibition pathways ( $\rightarrow$ ) can concern either the action of the targeted molecule or its production. Phosphorylation pathways are indicated by (๑) on arrows. Thin blue arrows indicate pathways that are hypothetical or not entirely understood in Clostridia. An inventory of the spore-formers possessed by sensors provides an overview of the environmental stimuli that could affect sporulation in Bacilli and Clostridia. Five sensor kinases, called KinA to KinE, have been reported in B. subtilis. The main sensor kinase KinA possesses three PAS domains (A, B and C) that sense different stimuli, such as the oxygen concentration via the $\mathrm{NAD}^{+} / \mathrm{NADH}^{\mathrm{ratio}}$ and redox potential (via the sensing of reactive oxygen species) or light intensity (via protein Sda that responds to DNA damages caused by light) [60]. The KinB protein, which does not possess PAS domains, senses anaerobic conditions [61] and potassium levels [56], while the KinC protein responds to plant signals and polyketides [40] and KinD to osmotic conditions and plant-derived signals $[34,40]$. The role of KinE remains to be elucidated. When they are stimulated, the five B. subtilis Kin sensors are autophosphorylated, and then phosphorylate the general response regulator of sporulation Spo0A via the successive intermediates Spo0F and Spo0B (Fig. 1). KinC is also able to directly phosphorylate Spo0A [33]. Phosphorylation of Spo0A P can be reversed by aspartate phosphatases such as Spo0E [28] and by the Rap phosphatases (RapA to RapK), which act by dephosphorylating the intermediary SpoOF $\sim$ P. Sporulation pathways are less well understood in Clostridia (thin blue arrows indicate pathways that are hypothetical or not entirely understood). Clostridium does not possess a multicomponent phosphorelay (Spo0F and Spo0B) and SinR inhibits Spo0A phosphorylation, while SinR inhibits production of Spo0A in Bacillus. The EDF-A and Phr pheromones have not yet been reported in Clostridium species if they exist, while they are sensed by Bacilli as indicators of cell density. In C. difficile the cytosolic HK CD1579 responds to carbon sources via the regulator CcpA.

EDF-A inhibits Rap proteins and thus participates in the increase in the SpoOA P level. Other pheromones, such as competence stimulatory factor (CSF), are involved in both competence at low concentrations and sporulation at high concentrations.

\subsubsection{Sporulation occurs in biofilms}

Sporulation can occur in response to high population density in colonies or in biofilms. Three major types of cells can co-exist in a biofilm: motile cells, matrix producers and sporulating cells. Sporulating cells derive mostly from matrix- 


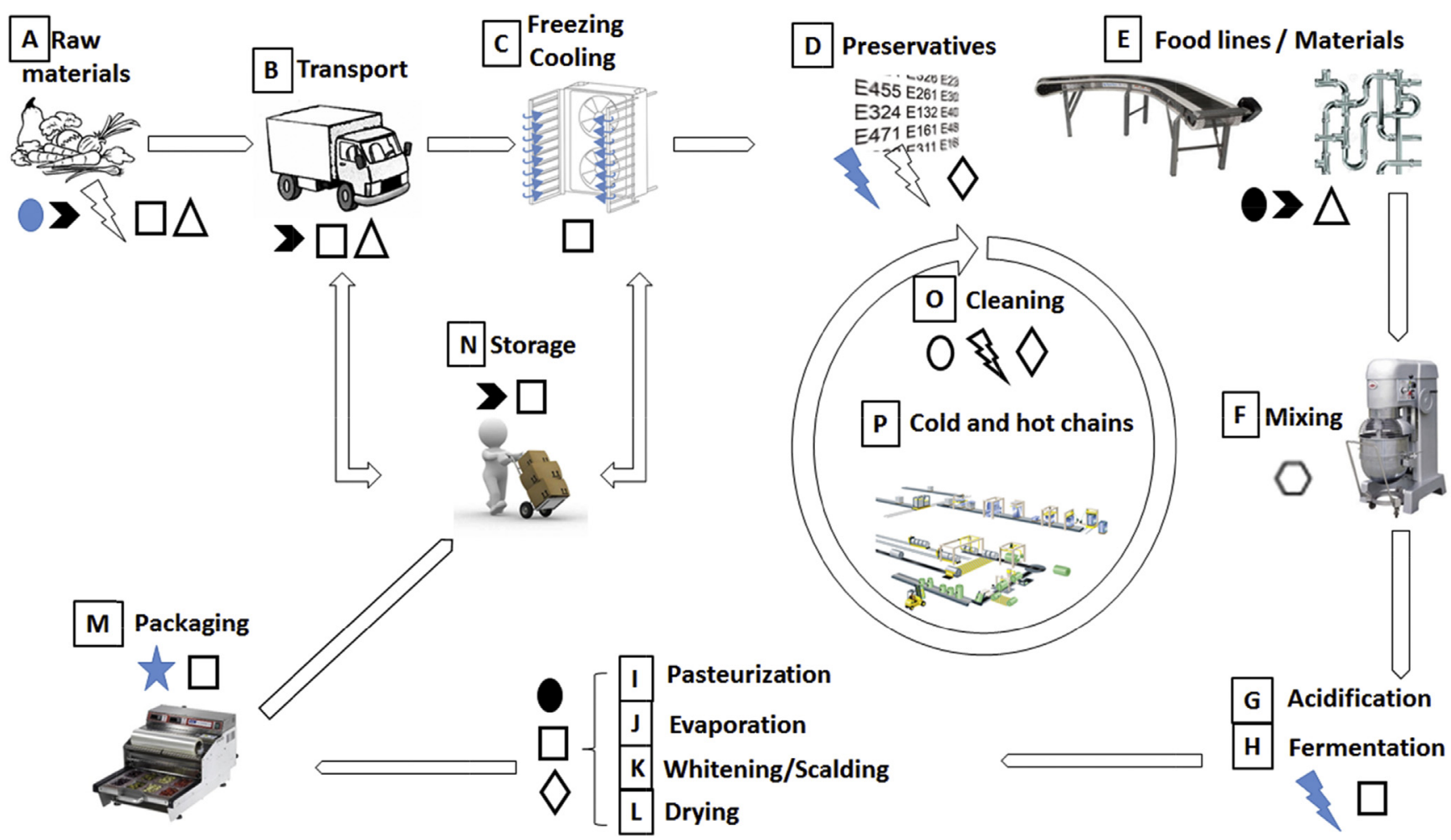

Fig. 2. Favorable steps for sporulation during a food process according to environmental factors. Different processes may be encountered in the food industry. The main factors that may modulate (empty symbols) or trigger sporulation of Clostridium (full blue symbols) or both Bacillus and Clostridium (full black symbols) are indicated at each step. Sporulation can be triggered by $\mathrm{pH}$ (Les paramètres nécessaires sont manquants ou erronés.) for Clostridium and by nutrients ( $\bigcirc$ ) and quorum-sensing signals $(\triangleright)$ for both. Modulating factors may also include $\mathrm{pH}$, nutrients and quorum-sensing signals as well as $\mathrm{a}_{\mathrm{w}}(\diamond)$, temperature $(\square)$, minerals $(\bigcirc)$, a variation in gas concentration $($ tis $)$, shear stress $(0)$ and the presence of other microorganisms $(\Delta)$.

producing cells and a few from motile cells, showing a hierarchical appearance of each population during the formation of a biofilm [32]. This can be explained by the activation of differentiation processes according to Spo0A $\sim \mathrm{P}$ concentrations: genes implicated in biofilm formation are activated at a low threshold of Spo0A P, while sporulation starts later, at a high level of Spo0A P [33]. The switch from matrix production, necessary for biofilm formation, to sporulation would imply a switch from phosphatase activity to the kinase activity of histidine-kinase (HK) KinD, one of the sensors involved in sensing external stimuli such as osmotic pressure [34] (Fig. 1). Moreover, surfactin, a signal molecule of biofilm formation, can break membranes leading to potassium ion loss. These potassium ions are sensed by another sensor, HK KinB, which leads to phosphorylation of Spo0A. Spores are preferentially formed on top of the colonies or the biofilms [32]. This could be linked to oxygen requirements and to the fact that the energy required to produce the biofilm matrix leads to severe nutrient starvation in these micro-environments. It should be noted that this preferential localization of spores at the interface with the air or with food or ingredients is favorable to air dissemination, and to germination when environmental conditions become favorable.

Biofilms can be found in many food processes in dairy, meat and vegetable industries. Spore-forming bacteria possess adhesion properties that allow them to adhere to surfaces on food lines to form biofilms (step E in Fig. 2). Biofilms of $B$. cereus have been found in dairy processing plants and on pasteurization lines (steps E and I in Fig. 2) as well as in dairy processing plants such as feeding units, tank trucks and air separators (steps A and B in Fig. 2) [36,37]. While sporulation was not strictly demonstrated in these examples, biofilms could contain $0.01 \%-10 \%$ of spores composed of B. cereus and $B$. subtilis biofilms [38]. It has also been shown that $B$. cereus is able to sporulate in mixed-culture biofilms [39]. Thus, the efficiency of cleaning steps during food processes might be limited by the ability of spore-forming bacteria to form biofilms on food lines. Another interesting example is $B$. subtilis, which colonizes the roots of Arabidopsis thaliana, with biofilm formation triggered by plant polysaccharides sensed by HK KinC and KinD [40] (Fig. 1). This would explain the prevalence of $B$. subtilis in the tomato rhizosphere, for example [41].

\section{Environmental factors that modulate sporulation}

\subsection{Generalities on the effects of environmental factors on sporulation initiation}

In general, unfavorable environmental conditions affect the metabolism of bacteria, leading to inhibition of both growth and sporulation. The general stress response is mainly 
governed by the sigma factor $\sigma^{\mathrm{B}}$ that controls genes involved in adaptation to many stresses, such as low temperatures. Interestingly, $\sigma^{\mathrm{B}}$ and $\mathrm{Spo} 0 \mathrm{~A} \sim \mathrm{P}$ are both involved in cellular survival and sporulation initiation [42]. As an example, $\sigma^{\mathrm{B}}$ activates production of $\mathrm{SpoOE}$, which is a main actor in Spo0A $\sim \mathrm{P}$ dephosphorylation in B. subtilis [43] (Fig. 1). In the genus Clostridium, only $C$. difficile possesses a $\sigma^{\mathrm{B}}$-like factor [44] and spoOE is absent from C. acetobutylicum, Clostridium botulinum and C. difficile [15]. However, a crosslink between stress response and sporulation also exists in Clostridium spp., as the sporulation factor $\sigma^{\mathrm{K}}$ is also involved in adaptation to environmental stress in C. botulinum ATCC3502 (Fig. 1) [45].

The ability to sporulate is dependent on the capacity to adapt according to environmental stresses. As sporulation is triggered by nutrient starvation and high cell density, it also implies that bacterial growth is needed prior to sporulation. Spore-forming bacteria display many eco-physiological characteristics, as they may be mesophilic, psychrophilic, thermophilic and acidophilic, leading to a broad range of potential sporulation niches $[6,46,47]$.

\subsection{Effects of environmental factors}

\subsubsection{Temperature}

The efficiency of sporulation is strongly affected by low temperature. Low temperatures induce lower sporulation and increase the duration of the sporulation process [54]. Suboptimal temperatures induce changes in the fatty acid composition of cell membranes in order to adapt their fluidity. More specifically, cold temperatures induce production of branchedchained and unsaturated fatty acids in B. subtilis in order to increase membrane fluidity [48]. The activity of HK KinA is inhibited by unsaturated fatty acids composed of 16-20 carbon atoms, such as oleic acid [49] (Fig. 1). The adaptive response to high or cold temperatures can participate in modulating sporulation. At a molecular level, only $15 \%$ of sporulation genes are induced by chill stress, in particular rapA that codes for a protein involved in inhibition of sporulation initiation by dephosphorylating SpoOF P (Fig. 1). Interestingly, 7-fold overproduction of Spo0A proteins was observed during $B$. subtilis growth at $20{ }^{\circ} \mathrm{C}$ rather than at $37^{\circ} \mathrm{C}$ [42]. However, as observed at $15^{\circ} \mathrm{C}$, sporulation was less efficient at $20^{\circ} \mathrm{C}$ compared to $37{ }^{\circ} \mathrm{C}$, with a sporulation delay and a lower final spore concentration. These results suggest that Spo0A plays a role not only in sporulation, but also in long term adaptation to cold stress and survival of coldadapted cells, supporting the theory of a cross-link between sporulation and adaptation to environmental conditions.

Some steps in food processes aim at limiting bacterial growth, such as storage at cold temperatures and maintenance of cold and hot chains (steps $\mathrm{N}$ and $\mathrm{P}$ in Fig. 2). However, these temperatures still allow growth and sporulation of psychrophilic or thermophilic bacteria that are selected by such steps. Moreover, processes such as heating or cooling (steps $\mathrm{C}$ and I to L in Fig. 2) could be slow enough to provide temperature and time ranges that allow growth and sporulation initiation of "fast growth" strains, such as $C$. perfringens (doubling time of 6-9 min between $43{ }^{\circ} \mathrm{C}$ and $45^{\circ} \mathrm{C}$ ). Other food processes such as scalding (step K in Fig. 2) can provide favorable temperatures for growth and sporulation of thermophilic bacteria.

\subsection{2. $p H$}

$\mathrm{pH}$ is a critical parameter that limits bacterial growth and sporulation in food. A maximum concentration of B. subtilis spores of $2.510^{9}$ spores $/ \mathrm{mL}$ was obtained at $\mathrm{pH} 8.0$ compared to $1.6 \cdot 10^{7}$ and $1.5 \cdot 10^{5}$ spores $/ \mathrm{mL}$ at $\mathrm{pH} 10.0$ and $\mathrm{pH} 6.0$, respectively in a defined medium [50]. Sporulation was also delayed by suboptimal $\mathrm{pH}$, with a maximum spore concentration obtained after 3 days at $\mathrm{pH} 8.0$ compared to 20 days at $\mathrm{pHs} 6.0$ and 10.0. In Clostridium, $\mathrm{pH}$ affects sporulation differently according to species: the optimum $\mathrm{pH}$ for sporulation of Thermoanaerobacterium thermosaccharolyticum (formerly Clostridium thermosaccharolyticum) is comprised between 5.0 and 5.5, whereas the maximal concentration of spores of $C$. perfringens is obtained at $\mathrm{pH} 7.0$, and no sporulation is observed at $\mathrm{pH} 5.5$ [51]. The way low $\mathrm{pH}$ acts on sporulation is not clear. It is believed to have an impact through an increase in production of reactive oxygen species [52] (Fig. 1) and by downregulating sigma factor $\sigma^{\mathrm{H}}$, which is necessary for initiation of sporulation [13,53].

In the environment, fruits and vegetables can be grown in soils with different levels of acidity, which can impact the growth and sporulation of spore-formers (step A in Fig. 2). Most foods have a low $\mathrm{pH}$, for instance fermented or acidified products (step D in Fig. 2). Somehow, lactic fermentation (step $\mathrm{H}$ in Fig. 2) can be slow enough to promote sporulation in soft cheeses such as camembert. Then, washing and cleaning processes can lead to a partial decrease in the $\mathrm{pH}$ of contaminating foods on lines (steps $\mathrm{E}$ and $\mathrm{O}$ in Fig. 2).

\subsubsection{Water activity}

Water activity is an important driver that limits bacterial growth and sporulation. A decrease in water activity from 0.996 to 0.985 reduces the final spore concentration of $B$. licheniformis AD978 in sporulation medium buffer by more than 4 logs [54]. Osmotic stress impacts sporulation by generating changes in fatty acid composition that could affect the HK KinA, leading to less efficient sporulation, as observed for the effect of temperature. Spo0A P concentrations are lower under hyperosmotic conditions. Osmotic shock blocks $B$. subtilis sporulation at the asymmetric division stage, with a $50 \%-70 \%$ reduction in $\sigma^{\mathrm{E}}$ and $\sigma^{\mathrm{F}}$, whose expression is an early sporulation sigma factor of the mother cell and the forespore, respectively [55]. We also hypothesize that the HK KinC of $B$. subtilis senses water activity through detection of increased levels of potassium ions [56], which is the first response to hyperosmotic shock (Fig. 1).

Water activity is used in the food industry as a weapon against bacterial growth by adding solutes such as salts or sugars to foods (step D in Fig. 2). An increase in water activity enhances sporulation. Food processes that could possibly be incriminated in a transient increase in water activity are 
scalding (step $\mathrm{K}$ in Fig. 2), the dilution effect of cleaning processes on food lines (step $\mathrm{O}$ in Fig. 2) and dilution processes directly linked to the type of food (e.g. fruit juices, sauces). On the other hand, drying processes (step L in Fig. 2) help lower water activity, which is liable to inhibit bacterial growth and sporulation.

\subsubsection{Aeration}

Aeration generates various gases that have different effects on sporulation. Few studies deal with sporulation in anaerobiosis, whereas sporulation is possible in anaerobic environments. Indeed, B. cereus can reach $10^{6}$ spores $/ \mathrm{ml}$ after culture for 4 days in anaerobiosis in a minimal medium at $37^{\circ} \mathrm{C}, \mathrm{pH}$ 7.4. However, B. cereus and B. thuringiensis produce 100 -fold fewer spores in anaerobiosis than in aerobiosis. Carbon dioxide also affects sporulation by enhancing sporulation of $C$. botulinum [57] or inhibiting sporulation of Bacillus anthracis [58]. According to the Bacillus species, sporulation in anaerobiosis is affected by other factors, such as the presence of nitrates which inhibit sporulation of Paenibacillus polymyxa and Paenibacillus macerans (both previously named Bacillus) in anaerobiosis, while it is necessary for a particular $B$. licheniformis strain [59]. The oxygen concentration is perceived by HK KinA via the $\mathrm{NAD}^{+} / \mathrm{NADH}$ ratio [60] while anaerobic conditions are sensed by KinB in B. subtilis [61] (Fig. 1). It has been shown that the presence of oxygen accelerates sporulation and, specifically, lysis of the mother cell in C. perfringens [62].

Soil and the intestines of insects and humans are anaerobic environments in which B. cereus and B. subtilis are able to sporulate [63]. Deprivation of oxygen can also be encountered after packaging under a modified atmosphere or vacuum packaging, such as for fresh fruits and vegetables that would favor particular species (step $\mathrm{N}$ in Fig. 2). Following this, regarding the effects of nitrates on sporulation, the presence of nitrates in foods may be due to their use as preservatives in processed meats, but also to agricultural practices like the use of fertilizers that increase nitrate levels in vegetables and water.

\subsubsection{Minerals}

Some minerals are needed for spore production. Sporulation of C. botulinum is enhanced with $1 \mathrm{mM}$ of $\mathrm{Mn}^{2+}$ and $\mathrm{Zn}^{2+}$, while the co-presence of $\mathrm{Fe}^{2+}$ and $\mathrm{Zn}^{2+}$ diminishes its sporulation [64]. The nature of the mineral salts also has its importance in sporulation: $\mathrm{CaCO}_{3}$ allows faster sporulation than $\mathrm{CaHPO}_{4}$ and gives a much higher spore yield than $\mathrm{Ca}(\mathrm{OH})_{2}$ for Clostridium sporogenes [65]. Sporulation of $B$. cereus is possible in a chemically defined medium MODS in anaerobiosis only in the presence of $\mathrm{MgCl}_{2}, \mathrm{MnCl}_{2}, \mathrm{CaCl}_{2}$ and $\mathrm{ZnCl}_{2}$ [66].

Foods are generally rich in minerals and oligo-elements. Enrichment in minerals can occur during processes such as drying treatments (step L in Fig. 2) which concentrate minerals by evaporation (step $\mathrm{J}$ in Fig. 2) or washing steps with calcareous waters (step $\mathrm{O}$ in Fig. 2), with the presence of nitrates that could enhance sporulation of some strains of $B$. licheniformis. On the contrary, cheese processes participate in mineral deprivation, with the slow acidification of soft cheeses leading to a decrease in calcium content.

\subsubsection{Presence of other microflora}

The presence of other microflora can affect sporulation indirectly. In the case of lactic starters, they can impact the growth and sporulation of spore-formers through competition for nutrients associated with rapid acidification. As an example, B. cereus cannot sporulate with Lactobacillus casei 2756 [67]. Another known mechanism is the production of nisin by Lactococcus lactis, commonly used as starter for cheese making. This cannibal toxin directly impacts the life cycle of spore-forming bacteria such as B. cereus [68].

Raw materials are naturally contaminated by different bacterial genera and species, either Gram-positive or Gramnegative, whether spore-formers or not. Thus, it seems judicious to consider the role of other microorganisms that contaminate raw materials, food lines and materials (steps A and $\mathrm{E}$ in Fig. 2). The fermentation process consists of using specific flora for food production leading to product acidification (step G in Fig. 2). For example, lactic acid bacteria are used as starters and ripening flora for cheese production or as protective flora in sausage.

\subsubsection{Light and shear stress}

Few studies deal with the effects of light and oxidative stress on sporulation. The final spore concentration of $B$. licheniformis is reduced by $60 \%$ when applying a high intensity light treatment during sporulation [69]. The effect of light on sporulation may be due to the damage caused on DNA, leading to production of the Sda protein, implicated in DNA repair and sporulation inhibition, by inhibiting autophosphorylation of KinA (Fig. 1) [70]. Shear stress is sensed by a NADH oxidase (NOX) that converts mechanical pressure into chemical signals: specific intracellular reactive oxygen species (siROS) that cause DNA damages (Fig. 1) [71]. As the sporulation process requires intact DNA, this could explain why spore production is lowered 17 -fold when siROS increase 10 -fold. In the food industry, shear stress may be encountered in a mixer or a mincing machine for delicatessens, for example.

\section{Combined effects of environmental factors throughout the food chain}

\subsection{The origin of spore prevalence in raw materials}

\subsubsection{Animal feeding}

Spores present in cow feed can resist the digestive process and then be found in milk via fecal contamination. This is why it is of great importance to limit sporulation in the farm environment. The upper layers of silage contain higher concentrations of spores (up to $5 \log _{10}$ spores/g). This has been related to oxygen penetration into the top $20 \mathrm{~cm}$ of silage, which depends on silage density, porosity and the rate of silage feeding. Yeast and mold growth can lead to an increase in 
silage $\mathrm{pH}$ (from 3.8 to 4.4 ) by consuming fermentable sugars and lactic acid; consequently, they may participate in creating anaerobic conditions just under the surface of the silage by consuming oxygen and because of the increase in microbial density. Anaerobic spore-formers like Clostridium tyrobutyricum are favored in these microenvironments [72]. While oxygen does not directly impact the sporulation of butyric acid bacteria, sporulation is possible following the sequential and combined actions of aeration, microbial growth and $\mathrm{pH}$. These three factors have been identified as modulating factors (step A in Fig. 2).

\subsubsection{Animal bedding}

The nature of bedding material also has an impact on sporulation, leading to an increase in spores that can contaminate cows' teats [73]. The spore load was found to be higher in organic bedding such as chopped straw or sawdust than in inorganic materials like sand. Indeed, growth (and consequently sporulation) cannot occur without organic matter. The $\mathrm{pH}$ of organic bedding is also important given that peat inhibited the growth of $B$. cereus (with a $\mathrm{pH}$ of 3.8), whereas chopped straw $(\mathrm{pH}$ 8.0) and sawdust (pH 7.0) did not. Temperature also affects the spore load in bedding, with the highest temperatures $\left(13-28{ }^{\circ} \mathrm{C}\right)$ found in the top 10-20 cm and in the back part of the bed where cows lay. Lastly, it has been demonstrated that the presence of feces and urine increased the spore load of bedding, as it constitutes organic matter intake and participates in increasing the $\mathrm{pH}$, which promotes sporulation (with $4.7 \log _{10}$ spores/g when stalls are bedded twice a week compared to $3.8 \log _{10}$ spores/g when stalls are bedded daily) without affecting growth (total counts of $B$. cereus were not affected by bedding frequency). Sporulation in beddings depends on the combined actions of organic matter intake, $\mathrm{pH}$ and temperature (see step $\mathrm{A}$ in Fig. 2).

\subsection{Sporulation on equipment at the origin of cross- contamination}

Sporulation needs previous growth and takes some hours to achieve. Environmental conditions suitable for growth and sporulation are rarely encountered for long periods during food processes. Consequently, sporulation is limited during food processing and cross-contamination must also be considered.

\subsubsection{Whole milk powder process}

Spore formation has been more extensively studied in dairy plants [10-12,74-76]. In the manufacture of whole milk powder, sporulation can occur at many stages of the process: in preheaters, heat exchangers, evaporators (steps $\mathrm{I}$ and $\mathrm{J}$ in Fig. 2), on food lines (step E in Fig. 2) or directly in milk during processing [12].

Throughout the manufacturing process of whole milk powder, favorable conditions for growth and sporulation have been identified in the product. The first step of the process consists of heating raw milk in preheaters at $50{ }^{\circ} \mathrm{C}$. In heat exchangers and evaporators, temperatures are comprised between $45{ }^{\circ} \mathrm{C}$ and $75^{\circ} \mathrm{C}$. These temperatures are favorable for the growth and sporulation of thermophilic bacteria. Combined with the duration of the runs, $6-8 \mathrm{~h}$ for raw milk treatments and $18 \mathrm{~h}$ for milk powder manufacturing, thermophilic bacteria with rapid growth (with a generation time of approximately $15-20 \mathrm{~min}$ ) could develop and sporulate in these environments. However, sporulation cannot occur through the evaporators as the milk becomes increasingly concentrated. This can be explained by the inability of thermophilic bacteria (Geobacillus species and Anoxybacillus flavithermus in this study) to grow in milk concentrate at low water activity. These results are consistent with those of Lane, who found that growth of Geobacillus stearothermophilus was limited in milk concentrate [77] (step L in Fig. 2).

Another key element when considering the increase in the spore load in milk during processing is cross-contaminations. Spores can be formed on food lines in biofilms or in foulant, thus constituting a source of recontamination of processed milk (step E in Fig. 2). For example, A. flavithermus was able to form biofilms and spores in milk reactors at $55{ }^{\circ} \mathrm{C}$ and $60{ }^{\circ} \mathrm{C}$. Indeed, according to the line structure, its cleanability and the cleaning frequency of lines, cells have time to form biofilms that may be resistant to flow during the passage of milk during processing. Spores that are preferentially formed at the top of biofilms (see Section 2.2.2) can be released in milk flowing through the reactor [78]. Secondly, with run after run of production, burnt milk could accumulate on the line, constituting nutrient sources for growth and sporulation.

\subsubsection{Vegetable preparation}

In the manufacture of canned vegetables, bacterial growth and sporulation could be promoted on the food lines at warm temperatures, coupled with long residence times [79,80]. Growth and sporulation of thermophilic bacteria could occur in whitening baths (step $\mathrm{K}$ in Fig. 2). Sporulation of $G$. stearothermophilus on debris of green beans on food lines was incriminated in cross-contamination (step E in Fig. 2). Indeed, vegetable debris can accumulate in whitening waters with a neutral $\mathrm{pH}$. Moreover, biofilms can be produced at different interfaces: on the edges of the whitening tanks or even at the surface of whitening baths.

\subsection{Complexity of sporulation niches}

The knowledge of the physiological capacities of sporeformers helps to identify environmental factors that impact growth and sporulation abilities (Fig. 2). However, targeting particular sporulation niches is not entirely straightforward, as many factors interact to modulate sporulation. Indeed, during the manufacture of whole milk powder, spore formation was affected from one production run to another [12]. These differences can be the result of a difference in milk quality that could affect sporulation according to nutrient availability, such as the lactose concentration, regarding the effects of sugars on sporulation (see Section 2.1) or the mineral composition (mainly calcium) (see Section 3.2.5). In addition, different 
microflora in milk could interfere with bacterial growth due to competition (see Section 3.2.6). Some temperature variations could occur from one run to another, which could affect growth and sporulation rates.

The difficulty in identifying specific sporulation niches also lies in bacterial selection according to food processes. Processes select some bacterial genera or species according to their growth and sporulation capacities $[9,75]$. As an example, A. flavithermus and G. stearothermophilus are rarely isolated from raw milk, unlike Bacillus species like B. licheniformis, $B$. subtilis and Bacillus pumilus [11]. A. flavithermus was predominant in the preheating sections, whereas A. flavithermus and Geobacillus species were both present in the evaporator and drying stages of a whole milk powder process [12]. The proportion of spore-formers is not conserved throughout the process. Generally, psychrotolerant bacteria like Paenibacillus sp. are mostly found in fluid milk, while mesophilic bacteria are preferentially found in shelf-stable milk products and thermophilic bacteria are more common contaminants of milk powder [10].

The relationship between particular sporulation environments and specific physiological capacities is illustrated with the panel of sensors (see Section 2.2) possessed by sporeformers to detect and respond to environmental stimuli. Indeed, the amino terminal domains of the sporulation sensor histidine kinases exhibit high variability between Bacillus species, suggesting activation of sporulation by different signals according to their niches. The ecological niches of four species of Bacillus were compared: G. stearothermophilus from an oil well, B. subtilis from a haystack, Bacillus halodurans in a salt lake and B. anthracis in a dying animal. It was proposed that their histidine kinases are specifically adapted to the corresponding environments, as the signalsensing domains are very different, whereas the catalytic domains of these histidine kinases are highly conserved so as to ensure the role of phosphorelay (Fig. 1) [81].

\section{Conclusions and insights}

The sporulation process is well described at the molecular and physiological levels. Moreover, sporulation environments have been reported in the food chain [1]. Knowledge of initiation and regulation pathways of sporulation allows a better understanding of (i) the environmental stimuli that trigger or promote sporulation and (ii) how they are sensed and integrated into the sporulation decision process. This study offers an overview of environmental factors that should be taken into account to help target sporulation environments in the food chain. However, it is not easy to predict precise sporulation niches from this inventory. Indeed, the main difficulties arise from the combined effects of environmental factors that affect growth and sporulation abilities. Identifying or predicting sporulation niches not only relies on sporulation abilities, but also on the general physiological capacities of spore-forming bacteria to grow, to form biofilms on food lines and then to sporulate. Spore formation throughout the food chain may also be the result of successive physico-chemical and microbial events specific to the ecophysiology of some genera or species.

\section{Conflicts of interest}

The authors declare no conflict of interest.

\section{Acknowledgments}

The authors would like to thank the editorial coordinators Didier Lereclus and Geraldine Camus for commissioned review.

\section{References}

[1] Carlin F. Origin of bacterial spores contaminating foods. Food Microbiol 2011;28:177-82.

[2] InVS. Surveillance des toxi-infections alimentaires collectives. 2013.

[3] Madslien EH, Rønning HT, Lindbäck T, Hassel B, Andersson MA, Granum PE. Lichenysin is produced by most Bacillus licheniformis strains. J Appl Microbiol 2013;115:1068-80.

[4] Andersson A, Ronner U, Granum PE. What problems does the food industry have with the spore-forming pathogens Bacillus cereus and Clostridium perfringens? Int J Food Microbiol 1995;28:145-55.

[5] Auger S, Ramarao N, Faille C, Fouet A, Aymerich S, Gohar M. Biofilm formation and cell surface properties among pathogenic and nonpathogenic strains of the Bacillus cereus group. Appl Environ Microbiol 2009; 75:6616-8.

[6] Heyndrickx M. The importance of endospore-forming bacteria originating from soil for contamination of industrial food processing. Appl Environ Soil Sci 2011:1-11.

[7] Veening J-W, Murray H, Errington J. A mechanism for cell cycle regulation of sporulation initiation in Bacillus subtilis. Genes Dev 2009;23:1959-70.

[8] Piggot PJ, Hilbert DW. Sporulation of Bacillus subtilis. Curr Opin Microbiol 2004;7:579-86.

[9] Postollec F, Mathot A-G, Bernard M, Divanac'h M-L, Pavan S, Sohier D. Tracking spore-forming bacteria in food: from natural biodiversity to selection by processes. Int J Food Microbiol 2012;158:1-8.

[10] Watterson MJ, Kent DJ, Boor KJ, Wiedmann M, Martin NH. Evaluation of dairy powder products implicates thermophilic sporeformers as the primary organisms of interest. J Dairy Sci 2014;97:2487-97.

[11] Miller RA, Kent DJ, Watterson MJ, Boor KJ, Martin NH, Wiedmann M. Spore populations among bulk tank raw milk and dairy powders are significantly different. J Dairy Sci 2015;98:8492-504.

[12] Scott SA, Brooks JD, Rakonjac J, Walker KMR, Flint SH. The formation of thermophilic spores during the manufacture of whole milk powder. Int J Dairy Technol 2007;60:109-17.

[13] de Hoon MJL, Eichenberger P, Vitkup D. Hierarchical evolution of the bacterial sporulation network. Curr Biol 2010;20:735-45.

[14] Talukdar PK, Olguín-Araneda V, Alnoman M, Paredes-Sabja D, Sarker MR. Updates on the sporulation process in Clostridium species. Res Microbiol 2015;166:225-35.

[15] Galperin MY, Mekhedov SL, Puigbo P, Smirnov S, Wolf YI, Rigden DJ. Genomic determinants of sporulation in Bacilli and Clostridia: towards the minimal set of sporulation-specific genes. Environ Microbiol 2012; $14: 2870-90$

[16] Sonenshein AL. CodY, a global regulator of stationary phase and virulence in Gram-positive bacteria. Curr Opin Microbiol 2005;8:203-7.

[18] Shih NJ, Labbé RG. Characterization and distribution of amylases during vegetative cell growth and sporulation of Clostridium perfringens. Can J Microbiol 1996;42:628-33.

[19] Long S, Jones D, Woods D. Initiation of solvent production, clostridial stage and endospore formation in Clostridium acetobutylicum P262. Appl Microbiol Biotechnol 1984;20:256-61.

[20] Mazmira MM. Effect of saccharides on growth, sporulation rate and $\delta$ endotoxin synthesis of Bacillus thuringiensis. Afr J Biotechnol 2012;11: $9654-63$. 
[21] Antunes A, Camiade E, Monot M, Courtois E, Barbut F, Sernova NV, et al. Global transcriptional control by glucose and carbon regulator CcpA in Clostridium difficile. Nucleic Acids Res 2012;40:10701-18.

[22] Varga J, Stirewalt VL, Melville SB. The CcpA protein is necessary for efficient sporulation and enterotoxin gene (cpe) regulation in Clostridium perfringens. J Bacteriol 2004;186:5221-9.

[23] Koide A, Perego M, Hoch JA. ScoC regulates peptide transport and sporulation initiation in Bacillus subtilis. J Bacteriol 1999;181: 4114-7.

[24] Shafikhani SH, Mandic-Mulec I, Strauch MA, Smith I, Leighton T. Postexponential regulation of sin operon expression in Bacillus subtilis J Bacteriol 2002;184:564-71.

[25] Awang G, Ingledew WM, Jones GA. The effect of fermentable carbohydrate on sporulation and butanol production by Clostridium acetobutylicum P262. Appl Microbiol Biotechnol 1992;38:12-6.

[26] Bischofs IB, Hug JA, Liu AW, Wolf DM, Arkin AP. Complexity in bacterial cell-cell communication: quorum signal integration and subpopulation signaling in the Bacillus subtilis phosphorelay. Proc Natl Acad Sci 2009;106:6459-64.

[27] Lazazzera BA. Quorum sensing and starvation: signals for entry into stationary phase. Curr Opin Microbiol 2000;3:177-82.

[28] Perego M. A new family of aspartyl phosphate phosphatases targeting the sporulation transcription factor Spo0A of Bacillus subtilis. Mol Microbiol 2001;42:133-43.

[29] Slamti L, Perchat S, Huillet E, Lereclus D. Quorum sensing in Bacillus thuringiensis is required for completion of a full infectious cycle in the insect. Toxins 2014;6:2239-55.

[30] Perego MA. Peptide export-import control circuit modulating bacterial development regulates protein phosphatases of the phosphorelay. Proc Natl Acad Sci U S A 1997;94:8612-7.

[31] Grossman AD, Losick R. Extracellular control of spore formation in Bacillus subtilis. Proc Natl Acad Sci U S A 1988:85:4369-73.

[32] Vlamakis H, Aguilar C, Losick R, Kolter R. Control of cell fate by the formation of an architecturally complex bacterial community. Genes Dev 2008:22:945-53.

[33] Fujita M, Gonzalez-Pastor JE, Losick R. High- and low-threshold genes in the Spo0A regulon of Bacillus subtilis. J Bacteriol 2005;187:1357-68.

[34] Rubinstein SM, Kolodkin-Gal I, McLoon A, Chai L, Kolter R, Losick R, et al. Osmotic pressure can regulate matrix gene expression in Bacillus subtilis. Mol Microbiol 2012;86:426-36.

[36] Marchand S, De Block J, De Jonghe V, Coorevits A, Heyndrickx M, Herman L. Biofilm formation in milk production and processing environments; influence on milk quality and safety. Compr Rev Food Sci Food Saf 2012;11:133-47.

[37] Sharma M, Anand S. Biofilms evaluation as an essential component of HACCP for food/dairy processing industry - a case. Food Control 2002; 13:469-77.

[38] Wijman JGE, de Leeuw PPLA, Moezelaar R, Zwietering MH, Abee T. Air-liquid interface biofilms of Bacillus cereus: formation, sporulation and dispersion. Appl Environ Microbiol 2007;73:1481-8.

[39] Faille C, Bénézech T, Midelet-Bourdin G, Lequette Y, Clarisse M, Ronse G, et al. Sporulation of Bacillus spp. within biofilms: a potential source of contamination in food processing environments. Food Microbiol 2014;40:64-74.

[40] Beauregard PB, Chai Y, Vlamakis H, Losick R, Kolter R. Bacillus subtilis biofilm induction by plant polysaccharides. Proc Natl Acad Sci U S A 2013;110:1621-30.

[41] Basamma RH, Kulkarni S. Prevalence of Bacillus subtilis in rhizosphere and severity of different diseases of tomato in Northern Karnataka. J Farm Sci 2015;28:351-5.

[42] Mendez MB, Orsaria LM, Philippe V, Pedrido ME, Grau RR. Novel roles of the master transcription factors Spo0A and B for survival and sporulation of Bacillus subtilis at low growth temperature. J Bacteriol 2004; 186:989-1000.

[43] Reder A, Albrecht D, Gerth U, Hecker M. Cross-talk between the general stress response and sporulation initiation in Bacillus subtilis - the $\sigma(\mathrm{B})$ promoter of spo0E represents an AND-gate. Environ Microbiol 2012;14: $2741-56$
[44] Dürre P, editor. Handbook on Clostridia. Boca Raton: Taylor \& Francis; 2005.

[45] Kirk DG, Zhang Z, Korkeala H, Lindstrom M. Alternative sigma factors SigF, SigE and SigG are essential for sporulation in Clostridium botulinum ATCC 3502. Appl Environ Microbiol 2014;80:5141-50.

[46] Guinebretiere MH, Girardin H, Dargaignaratz C, Carlin F, NguyenThe C. Contamination flows of Bacillus cereus and spore-forming aerobic bacteria in a cooked, pasteurized and chilled zucchini purée processing line. Int J Food Microbiol 2003;82:223-32.

[47] Ranieri ML, Huck JR, Sonnen M, Barbano DM, Boor KJ. High temperature, short time pasteurization temperatures inversely affect bacterial numbers during refrigerated storage of pasteurized fluid milk. J Dairy Sci 2009;92:4823-32.

[48] Diomandé SE, Nguyen-The C, Guinebretière M-H, Broussolle V, Brillard J. Role of fatty acids in Bacillus environmental adaptation. Front Microbiol 2015;6:813.

[49] Strauch MA, de Mendoza D, Hoch JA. cis-unsaturated fatty acids specifically inhibit a signal-transducing protein kinase required for initiation of sporulation in Bacillus subtilis. Mol Microbiol 1992;6:2909-17.

[50] Nguyen Thi Minh H, Durand A, Loison P, Perrier-Cornet J-M, Gervais P. Effect of sporulation conditions on the resistance of Bacillus subtilis spores to heat and high pressure. Appl Microbiol Biotechnol 2011;90:1409-17.

[51] Pheil CG, Ordal ZJ. Sporulation of the "thermophilic anaerobes." Appl Microbiol 1967;15:893-8.

[52] Wilks JC, Kitko RD, Cleeton SH, Lee GE, Ugwu CS, Jones BD, et al. Acid and base stress and transcriptomic responses in Bacillus subtilis. Appl Environ Microbiol 2009;75:981-90.

[53] Cosby WM, Zuber P. Regulation of Bacillus subtilis sigmaH (spoOH) and AbrB in response to changes in external pH. J Bacteriol 1997;179: 6778-87.

[54] Baril E, Coroller L, Couvert O, El Jabri M, Leguerinel I, Postollec F, et al. Sporulation boundaries and spore formation kinetics of Bacillus spp. as a function of temperature, $\mathrm{pH}$ and a(w). Food Microbiol 2012;32:79-86.

[55] Ruzal SM, López C, Rivas E, Sánchez-Rivas C. Osmotic strength blocks sporulation at stage II by impeding activation of early sigma factors in Bacillus subtilis. Curr Microbiol 1998;36:75-9.

[56] Grau RR, de Oña P, Kunert M, Leñini C, Gallegos-Monterrosa R, Mhatre E, et al. A duo of potassium-responsive histidine kinases govern the multicellular destiny of Bacillus subtilis. mBio 2015;6:581-615.

[57] Craven SE. Increased sporulation of Clostridium perfringens in a medium prepared with the prereduced anaerobically sterilized technique or with carbon dioxide or carbonate. J Food Prot 1988;51:700-6.

[58] Sterne M. Anthrax. In: Infect. Dis. Anim. Dis. Due Bact.,vol. 1. , London: Butterworth; 1959. p. 16-52.

[59] Couchot KR, Maier S. Anaerobic sporulation in facultatively anaerobic species of the genus Bacillus. Can J Microbiol 1974;45:1291-6.

[60] Taylor BL, Zhulin IB. PAS domains: internal sensors of oxygen, redox potential and light. Microbiol Mol Biol Rev 1999;63:479-506.

[61] Kolodkin-Gal I, Elsholz AKW, Muth C, Girguis PR, Kolter R, Losick R. Respiration control of multicellularity in Bacillus subtilis by a complex of the cytochrome chain with a membrane-embedded histidine kinase. Genes Dev 2013;27:887-99.

[62] Ahmed M. Sporulation and germination of spores of Clostridium perfringens. Retrospective theses and dissertations. 1970. Paper 4207.

[63] Tam NKM, Uyen NQ, Hong HA, Duc LH, Hoa TT, Serra CR, et al. The intestinal life cycle of Bacillus subtilis and close relatives. J Bacteriol 2006;188:2692-700.

[64] Kihm DJ, Hutton MT, Hanlin JH, Johnson EA. Zinc stimulates sporulation in Clostridium botulinum 113B. Curr Microbiol 1988;17:193-8.

[65] Mah J-H, Kang D-H, Tang J. Effects of minerals on sporulation and heat resistance of Clostridium sporogenes. Int J Food Microbiol 2008;128: $385-9$.

[66] Abbas AA, Planchon S, Jobin M, Schmitt P. A new chemically defined medium for the growth and sporulation of Bacillus cereus strains in anaerobiosis. J Microbiol Methods 2014;105:54-8.

[67] Rossland E, Langsrud T, Sorhaug T. Influence of controlled lactic fermentation on growth and sporulation of in milk. Int J Food Microbiol 2005;103:69-77. 
Version définitive du manuscrit publiée dans / Final version of the manuscript published in :

Research in Microbiology (2016), 10 p., DOI: 10.1016/j.resmic.2016.10.006

Journal homepage : http://www.elsevier.com/locate/resmic

[68] López D, Vlamakis H, Losick R, Kolter R. Cannibalism enhances biofilm development in Bacillus subtilis. Mol Microbiol 2009;74:609-18.

[69] Propst-Ricciuti C, Lubin L. Light-induced inhibition of sporulation in Bacillus licheniformis. J Bacteriol 1976;128:506-9.

[70] Rowland SL, Burkholder WF, Cunningham KA, Maciejewski MW, Grossman AD, King GF. Structure and mechanism of action of Sda, an inhibitor of the histidine kinases that regulate initiation of sporulation in Bacillus subtilis. Mol Cell 2004;13:689-701.

[71] Sahoo S, Rao KK, Suraishkumar GK. Reactive oxygen species induced by shear stress mediate cell death in Bacillus subtilis. Biotechnol Bioeng 2006;94:118-27.

[72] Vissers MMM, Driehuis F, Te Giffel MC, De Jong P, Lankveld JMG. Concentrations of butyric acid bacteria spores in silage and relationships with aerobic deterioration. J Dairy Sci 2007;90:928-36.

[73] Magnusson M, Christiansson A, Svensson B. Bacillus cereus spores during housing of dairy cows: factors affecting contamination of raw milk. J Dairy Sci 2007;90:2745-54.

[74] Murphy PM, Lynch D, Kelly PM. Growth of thermophilic spore forming bacilli in milk during the manufacture of low heat powders. Int J Dairy Technol 1999;52:45-50.
[75] Ghellai L, Moussaboudjemaa B. Aerobic spore-forming bacteria in the ultra high temperature milk produced in the north west of Algeria. J Agric Sci Technol 2013:697-702.

[76] Van Houdt R, Michiels CW. Biofilm formation and the food industry, a focus on the bacterial outer surface: biofilm formation and the bacterial outer surface. J Appl Microbiol 2010;109:1117-31.

[77] Lane AN. Thermophiles in Milk Powder. 1982.

[78] Burgess SA, Brooks JD, Rakonjac J, Walker KM, Flint SH. The formation of spores in biofilms of Anoxybacillus flavithermus. J Appl Microbiol 2009; 107:1012-8.

[79] Rigaux C, André S, Albert I, Carlin F. Quantitative assessment of the risk of microbial spoilage in foods. Prediction of non-stability at $55{ }^{\circ} \mathrm{C}$ caused by Geobacillus stearothermophilus in canned green beans. Int J Food Microbiol 2014;171:119-28.

[80] Durand L, Planchon S, Guinebretiere M-H, André S, Carlin F, Remize F. Contamination pathways of spore-forming bacteria in a vegetable cannery. Int J Food Microbiol 2015;202:10-9.

[81] Stephenson K, Hoch JA. Evolution of signalling in the sporulation phosphorelay. Mol Microbiol 2002;46:297-304. 